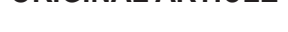

\section{Analysis on the Art Skills of Editing Radio and TV News in the Era of Financial Media}

\author{
Siyuan Wang \\ Chuangying Light Media Co., Ltd.
}

Abstract: Under the background of the new era, network technology, information technology and new media technology have been applied to various fields, effectively promoting social progress and industry development. In particular, the application of big data, cloud computing and multimedia technology in the radio and television industry not only accelerates the speed of information transmission and increases the number of information dissemination, but also truly realizes information sharing and promotes the sustainable development of the radio and television industry. Under the background of the new era, the information collection and processing technology and editing technology in the radio and television news industry have been improved, which also puts forward new requirements for the editing skills of radio and television news. Based on the author's own news practice, through analyzing the editing skills of radio and television news in the new era, the author puts forward some thoughts and countermeasures to provide useful reference for more radio and television news from the north.

Keywords: New Era; Radio and Television News; Editing Skills

At the opening ceremony of the 19th national congress, general secretary Xi Jinping put forward the new? The new definition, new tasks and new requirements of the times have also prompted various fields and industries to make continuous changes in ways and concepts. In recent years, the progress of science and technology has accelerated the development of Internet media and mobile phone media, increasing the application value of information technology in the field of radio and television, greatly improving people's living standards, and enabling people to obtain more news information through the Internet and mobile phones. Under the background of the new era, the development of science and technology has enabled the application of information technology and network technology to realize information sharing, bringing opportunities to the radio and television industry, as well as great challenges to the social status and influence of traditional media. Therefore, for radio and television news practitioners, it is necessary to continuously improve and innovate news editing skills to meet the requirements of the new era for the radio and television industry.

\section{The characteristics of news gathering and editing work in the era of financial media}

\subsection{Increase in the total amount of news information}

With the arrival of the era of financial media, news gathering and editing has undergone certain changes, showing new development characteristics. First of all, it is reflected in the increase of information collection during news gathering and editing. With the popularity of the Internet, people's production and life depend more and more on the Internet. Cyberspace provides a new carrier for the dissemination of information, making the total amount of information in the whole society increase explosively. News gathering and editing work needs to discover and find news points with reporting value from the huge amount of information in the implementation process. Although the source

Copyright (C) 2019 Siyuan Wang

doi:10.18282/inm.v2i1.317

This is an open-access article distributed under the terms of the Creative Commons Attribution Non-Commercial License (http://creativecommons. org/licenses/by-nc/4.0/), which permits unrestricted non-commercial use, distribution, and reproduction in any medium, provided the original work is properly cited. 
of information for news gathering and editing work is expanded to a certain extent, it actually increases the difficulty of news gathering and editing work, which requires editors to improve their ability of information collation and induction.

\subsection{News editors tend to be diversified}

The news gathering and editing work in the era of financial media also shows the characteristics of diversification of gathering and editing subjects. The emergence of various new media and self-media platforms has broadened the channels and channels of news information dissemination. Everyone can establish their own social accounts through the new media platforms. The main body of news gathering and editing work is no longer limited to the relevant staff of television stations or newspapers. People can record hot events happening around them through mobile phones or computers, collect and edit relevant news information, and publish through their own social accounts. This not only enriches the forms of news gathering and editing, but also poses no small threat to the traditional news gathering and editing staff, prompting them to actively explore innovative paths.

\subsection{Realize the efficient dissemination of news information}

With the arrival of the era of financial media, the efficient dissemination of positioning information has gradually been realized. The network world is changing rapidly. News hot spots spread through various new media and selfmedia platforms can create millions of readings in just a few minutes. People can learn about the corresponding hot events through mobile phones, computers, tablets and other terminals at any time. This provides certain reference and reference for the innovation of news gathering and editing work. News gathering and editing work can make use of the characteristics of high-speed information dissemination to dig up news materials in depth and improve news editing and planning capabilities. But at the same time, news editors must check the authenticity of the information and resolutely implement the working principle of not spreading rumors and false information.

\subsection{The real-time interaction of news is enhanced}

The news gathering and editing work in the financial media era also shows the characteristics of strong realtime interaction. Compared with traditional news gathering and editing work, news gathering and editing personnel are no longer only editors and producers of news content, but also take on the role of information transmission and communicators in the process of news release. People are willing to express their opinions and opinions on a hot social event. News gathering and editing personnel should pay attention to collecting and collating public opinions, realize online interaction and communication with people, and give full play to the social value of news work.

\section{The financial media era news gathering and editing work deficiencies}

\subsection{Difficult to grasp news hot spots}

First, journalists lack a sensitive sense of news smell and cannot catch news events of public interest in time, resulting in the loss of audiences. Second, there are still staff members who use traditional methods when collecting news, which cannot keep pace with the development of the times. As a result, there are already some similar news on the Internet before many explosive hot news can be compiled and distributed. There is a significant lag in news reporting, and the best reporting time for hot news has disappeared. Therefore, if journalists cannot grasp valuable content in time after the news broke out, it will affect the quality of news gathering and editing.

\subsection{The quality of work is not high}

Under the background of the current era, new and high technologies and tools are constantly appearing, which provides many conveniences for journalists and lightens their workload. However, the quality of some people's work is not high enough to meet their needs. At this stage, editors generally collect information remotely based on network technology, rather than in-depth on-site understanding of the situation, which is not desirable. The pace of people's life is accelerating, and the public uses more fragmented time to browse news. Considering this, staff members need to pay attention to information streamlining when editing news, and screen out the most important information through effective methods to meet public needs.

\subsection{Lack of professional ability}


Journalists are the practitioners of news gathering and editing. The quality of news gathering and editing depends on their professional ability. However, in the era of financial media, many journalists have the problem of insufficient professional ability. They do not pay attention to improving their professional ability. Some people pursue the number of news hits in their work but do not pay attention to the authenticity of news.

\section{Financial media era news editing skills}

\subsection{Carry out news gathering and editing work from various angles and in all directions}

In the era of financial media, some news media release some unverified information for the purpose of enhancing news attraction and meeting the needs of some audiences. This behavior is not consistent with the professional ethics of journalists. As far as the social level is concerned, such behaviors will affect the audience's satisfaction with the news media. They will lose confidence in the media that releases such information and the media will lose some audience. Therefore, journalists should avoid this kind of situation, strictly abide by their own professional ethics, actively and actively implement relevant work, fully investigate the news facts, and ensure the authenticity and objectivity of the news. For sudden news events, editors should ensure that the news materials are true, spend as little time as possible to verify and obtain evidence, and follow up the development of subsequent events. News editors should be responsible for the news they report and enhance their social responsibility.

\subsection{Improve editing skills and pay attention to the needs of the audience}

In the era of financial media, traditional TV news reports appear more rigid and cannot meet the diverse needs of the public. Therefore, in order to improve the effect of news editing, editors should add new vitality elements to TV news. In the process of editing, editors should also pay attention to empathy, think about the audience of the news, dig out the news information they like and are interested in, and then better meet the needs of the audience.

\subsection{Be familiar with new media technology and make rational and effective use of media resources}

Journalists should not only comprehensively collect and integrate news information in their work, but also pay attention to the application of various media platforms and communication channels, give full play to their role, and integrate the working resources of their opponents in order to promote the dissemination of news information and accurately capture news hot spots. Through the effective application of new media technology, the key information that the public wants to obtain is extracted from a large amount of information.

\subsection{The perfection of press releases depends on condensation}

In order to ensure the efficiency and quality of news gathering and editing, news gathering and editing staff should pay attention to the hot and cold degree of topic selection, that is, they can use the best method to show the relevant elements when they know roughly the place and time of news events but do not know the specific reasons and results. When explaining the event, you can also change the angle. Grasp the detailed description; He is good at summarizing the most important content in news with deep concise language, revealing the theme, paying attention to the concise information, and striving to write the most attractive and concise facts in the most concise form and language. Pay attention to the combination of text and pictures. Reporters take some pictures of the scene. Editors can record the events in chronological order. Then find out the most representative photos with concise and precise text description to explain the cause and background of the incident. The choice of news pictures is very important. It should reflect the requirements of news and visual arts at the same time. It is novel, representative, artistic and penetrating, and impressive. For example, there is news that a forest public security bureau in Shanxi province has seized a case of illegal acquisition and transportation of wild animals, confiscated three badgers illegally acquired and transported, and fined the violator 12,000 yuan. The original title of the press release was "Shanxi Forest Police Seize Illegal Acquisition of Wild Animals, Badger Case", which was later revised to "Please Let Wild Animals Live". Through such adjustment, the temperature of the news can be raised and the audience can have strong emotional resonance. Through the combination of words and pictures, the news theme can be vividly and intuitively expressed. The news directly quotes the police's words as detailed description in the narration, which increases the seriousness and authenticity of the news. 


\section{Conclusion}

To sum up, in the era of financial media, news gathering and editing work should adapt to the requirements of the development of the times, improve the efficiency and quality of news gathering and editing work, and enhance the professional quality level of gathering and editing personnel. Editors should improve their comprehensive ability, master effective news editing skills and produce more influential and excellent news works. At the same time, they should follow the principles of seeking truth from facts and observing the essence of phenomena to promote the great development of news editing.

\section{References}

1. Liang He. Research on Innovative Strategies of TV News Editing in Financial Media Era [J]. Satellite TV and Broadband Multimedia, 2019(08):116-117.

2. Gu Lei, Ding Ruan Yu. Analysis of County News Editing Art Skills in Financial Media Era [J]. Communication Research, 2018,2(36):116.

3. Jiao Xiaoyan. Discussion on Art Skills of County Radio and TV News Editing in the Era of Financial Media [J]. TV Guide, 2018(08):95.

4. Li Yuanyuan. Innovative ways of TV news editing in the financial media era [J]. Western Radio and Television, 2018(02):158.

5. Zhao Chongzhen. Analysis of County Radio and TV News Editing Art Skills in Financial Media Era [J]. News Communication, 2017(12):143+145. 